\title{
La Civilidad en las Castas Veladas del México Actual
}

\author{
Horacio GONZÁLEZ LÓPEZ \\ Instituto de Investigaciones Psicológicas, Universidad Veracruzana, México. \\ horacio50@gmail.com \\ Irene MARQUINA SÁNCHEZ \\ Facultad de Idiomas, Universidad Veracruzana, México \\ imarquinasan@gmail.com \\ Celia Cristina CONTRERAS ASTURIAS \\ Facultad de Idiomas, Universidad Veracruzana, México \\ celiacca@yahoo.com
}

Recibido: 10-09-2012

Aceptado: 19-12-2012

\begin{abstract}
Resumen
El escrito aborda el problema de los actuales patrones de convivencia de los mexicanos, a partir del concepto de Casta, manejado durante la Colonia. En la Nueva España ese concepto significó 'mezcla racial’ y, con ese significado, el concepto integró dos distintos horizontes semánticos: el de mezcla de razas y el de estrato social. Durante la Colonia, la casta ubicaba a las personas dentro de dos distintos horizontes, uno basado en características somáticas, y otro, basado en la jerarquización social. Hoy, los significados novohispanos de las palabras 'casta' y 'raza' están ausentes. El tema de las diferencias somáticas ha desaparecido del campo del análisis de la identidad del mexicano, pero esas diferencias todavía son señaladas como signo de diferencias de riqueza económica, educativa y cultural, y sobre todo, como signo de maneras de trato interpersonal, es decir, como signos de diferencias de civilidad.
\end{abstract}

Palabras clave: castas; civilidad; raza; somático; mestizaje; México.

\section{The Civility in the Veiled Castes of Present Mexico}

\begin{abstract}
This paper deals with the problem of the present patterns of living together of Mexicans, starting from the concept of Caste, managed during the Colonial times. In the New Spain, that concept meant 'racial mixture' and, with that meaning, the concept integrated two different semantic horizons: that of the mixture of races and that of the social stratum. During the Colonial times, the caste placed people in two different horizons, one based on somatic characteristics, and another, based on social hierarchy. Today, the Novohispanic meanings of the words 'caste' y 'race' are absent. The issue of the somatic differences has disappeared from the analysis of the identity of the Mexican, but those differences are still underlined as a sign of differences of economic, educative and cultural wealth, and, overall, as a sign of interpersonal manners, that is, as signs of differences of civility.
\end{abstract}


Key words: caste; civility; race; somatic; miscegenation; Mexico

\section{Referencia normalizada}

González López, H., Marquina Sánchez, I., Contraras Asturias, C. (2013). "La Civilidad en las Castas Veladas del México Actual”. Política y Sociedad, Vol.50 Núm 2: 517-542

Sumario: Introducción. 1.Objetivos. 2. De Raza y de Castas. 3.Las Castas Veladas del México Actual. 4.Conclusión. Bibliografía

\section{Introducción}

Por su etimología la palabra 'casta' remite al significado de 'puro', de ahí la palabra 'castidad' (Gómez de Silva, 1988). Sin embargo, cuando la palabra es empleada para hablar de personas, esa misma palabra remite a los significados de 'ascendencia', de 'linaje' (Diccionario de la Lengua Española, 1992; Casares Sánchez, 2000) y, por esta vía, esa palabra remite a los significados de 'raza', de 'limpieza de sangre' y, por lo tanto, de 'continuidad genealógica' y de 'genealogía' (Hering Torres, 2003; Martínez, 2008).

En la Nueva España, al igual que en el resto de las Colonias de los primeros siglos de la dominación española de América, el significado de la palabra 'casta' integraba dos distintos horizontes semánticos. Uno sería el de raza, o más específicamente, el de una mezcla de razas que estaría confinada dentro de un mismo estrato social. El segundo horizonte semántico sería ése de estrato social. En este sentido, durante la Colonia, el significado de la palabra 'casta' se abría en una doble semántica. Así, a partir de los primeros siglos de la Nueva España, la casta ubicaba a las personas no sólo dentro de un muy amplio y, sobre todo, ambiguo horizonte de características físicas, morfológicas, corporales, o somáticas, sino dentro de un horizonte de jerarquización social sustentado en esas características. Mientras que en la práctica las fronteras de este último horizonte eran ambiguas y, por lo tanto, dinámicamente permeables, en su concepto ese mismo horizonte era pensado como cerrado en sí mismo.

En el habla cotidiana del México actual, es poco frecuente el empleo de la palabra 'casta' para hacer estricta referencia a la ascendencia familiar, al linaje, a la genealogía o a la 'limpieza de sangre' de una persona, y es mucho menos frecuente su empleo para ubicar a una persona o a un grupo de personas, dentro de un específico nivel social, a su vez ubicado al interior de una estructura social, la cual habría sido establecida y mantenida por medio de un cuidado de líneas directas y estrechas de parentesco, que tendrían por signos todo un conjunto de características físicas, morfológicas, corporales o somáticas. Todo esto correspondería al concepto 
disciplinario —sociológico y antropológico — de Casta (Ferrando Badía, 1974; Pritt-Rivers, 1971).

Aun así, ha habido quienes recientemente han empleado esa palabra, en México, para hacer referencia a alguna forma de continuidad familiar. Así, por ejemplo, Mayagoitia (1998) emplea esa palabra para hablar del origen decimonónico de las familias y 'linajes' de algunos abogados mexicanos:

'...de casta le viene al galgo ser rabilargo', y para hablar de la continuidad en la producción de abogados célebres dentro de esas familias, dentro de esos linajes.

En el México de hoy, el significado y la palabra misma de 'raza', están ausentes en los léxicos empleados en los discursos cotidianos acerca de las personas, y ese significado y esa palabra están igualmente ausentes en los léxicos de los discursos institucionales y en los léxicos de los discursos académicos.

Esa ausencia ha terminado por expulsar el tema de las características físicas y corporales — o somáticas - del mexicano, del horizonte de la reflexión acerca de su identidad. La identidad, en tanto que condición psicológica, para sí misma implica un juego de conciencia y de inconciencia del Sí Mismo (Elias, 1990: 11; 116); un juego de conciencia e inconciencia del propio cuerpo, y un juego de conciencia e inconciencia de los significados que los demás otorgan a ese mismo cuerpo propio (Merleau-Ponty, 1945: 87-232; Elias, 1987: 34; 100; 115; 123; 142).

Sin embargo, a pesar de la expulsión del tema de las características morfológicas o somáticas del mexicano, de la reflexión acerca de su identidad, esas características han seguido ahí. La publicidad televisiva muestra, según su fuente y su destino, dos distintos mexicanos. La publicidad colocada por el Gobierno Federal mexicano en la televisión, nos presenta mexicanos morenos y de cabello obscuro. La publicidad televisiva de alimentos, de artículos de belleza, de automóviles y de 'productos' bancarios, entre otros, nos presenta mexicanos de piel blanca y cabello claro. Al margen de sus fuentes, la publicidad televisiva en México tiene claramente dos distintos destinos sociales y humanos.

Mientras que la revista Ebony fue fundada en 1945 como expresión estadounidense de la belleza afroamericana (Clarke, 2010; Myers y Margavio, 1983; Thimmesch, 1975), en estos principios del siglo XXI, en México todavía no podemos identificar una revista expresamente dedicada a la construcción conceptual de la belleza de la gran mayoría de los cuerpos mexicanos. En México, todavía no podemos identificar una revista expresamente dedicada a la estética de la gran masa trabajadora, explotada y auto señalada por sus características somáticas. Monsivais inicia su abordaje del problema de la 'estética de la naquiza', es decir, el problema de la estética de ese mexicano que es la versión actual del mestizaje histórico, no sólo como el problema de ése que es feo a la luz de un ideal de belleza física el cual, el mismo Monsivais, no identifica, sino como el problema de ése que niega tal fealdad al convertirla en mera envoltura: 'No es que esté feo, es que estoy mal envuelto' (Monsivais, 2010).

Lentamente, desde mediados del siglo pasado, emerge el concepto de Biotipo Humano, como una noción que busca remplazar al concepto de Raza, aun cuando el 
concepto biológico de Biotipo no deja de estar emparentado con el concepto biológico de Raza, y aun cuando, desde los años treinta del siglo ahora pasado, el concepto de Biotipo haya sido objeto de algunas revisiones críticas dentro de su disciplina de origen (Downie, 2010; Smith, 1941; Thorpe, 1930).

De acuerdo con Lagunas y López (2004: 7), en la década de los años cuarenta se iniciaron, en México, algunos estudios de corte 'biotipológico', cuyos resultados fueron integrados en el libro de Gómez Robleda - y colaboradores - sobre la biotipología de los Otomíes (Gómez Robleda, 1961). No obstante, esos estudios son la continuación de toda una perspectiva evolucionista y positivista —en el espíritu estrictamente comteano de esta última posición-, acerca del problema de la raza, perspectiva que fue introducida en México a mediados del siglo XIX, por los equipos científicos llegados con la invasión francesa (Urías Horcasitas, 2000-2001: 29), perspectiva que fue posteriormente adoptada como parte de las propuestas ofrecidas para la comprensión de diversidad humana y étnica del país y, sobre todo, como parte de las soluciones al problema planteado por la función acordada a los indígenas, por las élites, en el atraso económico, social y cultural del país: 'el indio forma parte de los factores que determinan el atraso económico, social y cultural del país' (Urías Horcasitas, 2000-2001: 28-29).

Esa perspectiva —esencialmente morfológica y somatométrica, y fuertemente ligada a las posiciones sostenidas dentro de la medicina legal del siglo XIXabrazaba la tesis de la superioridad racial de ser humano europeo y blanco. Con el triunfo de los Liberales mexicanos sobre los invasores franceses, se emprende una búsqueda de la homogeneización racial, la cual suponía que el mestizaje sería una vía para acercar las razas inferiores — necesariamente indígenas o mestizas de piel obscura - a la superioridad de las razas de piel más pálida, en el entendido de que la entera humanidad era el resultado de un proceso de monogénesis, que unificaría a todos los humanos en una pareja teórica primigenia, origen de todos los seres humanos sobre la tierra (Urías Horcasitas, 2000-2001: 29).

La anterior suposición sirvió de base al inicio de un lento y subrepticio proceso de blanqueado del mestizaje, cuando esta última noción y condición fue entronizada, en las primeras décadas del siglo XX, como La dimensión humana de la nación mexicana y como $\mathrm{La}$ condición, por excelencia, de la unificación de esa misma dimensión (Urías Horcasitas, 2000-2001: 35; Bazave Benítez, 1992).

En un proceso histórico relativamente rápido, a partir de la independencia se iniciaron distintas transformaciones conceptuales. Mientras que físicamente se expulsó a los españoles, conceptualmente se expulsaron las nociones de Indígena y de Indio, se abolió la esclavitud, aunque se mantuvieron las condiciones de sometimiento económico vigentes desde principios de la Colonia, y se convirtió en 'ciudadanos' a los indígenas y a miembros de las castas, como si una transformación conceptual implicara, directa e inmediatamente, una transformación de la realidad.

La repetición de la palabra "proceso" en los párrafos anteriores busca señalar tres suposiciones: $1^{\circ}$ ) la 'entera humanidad' sería resultado de cambios de monogénesis, los cuales ocurrirían en términos de un 'ceder-hacia-delante’ (pro- 
cedere), es decir, en términos de un proceso; $2^{\circ}$ ) en la Nueva España y más tarde en el México surgido del triunfo de la Reforma, daría inicio un proceso de blanqueado del mestizaje, es decir, daría inicio a una operación de 'ceder-hacia-delante' del blanqueado del mestizaje; y $3^{\circ}$ ) los conceptos vigentes en los discursos sostenidos a partir de la Independencia de México, serían resultado de cambios que se darían, también, en términos de un proceso - de un 'ceder-hacia-delante' -, el cual sería esencialmente histórico.

A pesar de la ausencia de la palabra 'raza' y de sus significados centrados en las características físicas, morfológicas, corporales o somáticas de las personas, a pesar de la emergencia de un concepto antropológico de Biotipo, destinado a mantener una igualdad universal por encima de cualquier diferencia, sin por lo tanto incursionar en el problema de la Naturaleza Humana, los mexicanos nos acomodamos - y buscamos acomodarnos - en nuestros 'mapas' geo-políticos (Wright and Ellis, 2006): barrios, colonias, fraccionamientos, delegaciones, municipios, etc., en términos de nuestras diferencias y similitudes de tonos de la piel, no porque ellas sean determinantes de nuestros acomodos, sino porque ellas son parte importante del conjunto de signos que anuncia riqueza - o pobrezaeconómicas, y porque ese mismo conjunto de signos anuncia distintas maneras de relacionarse con la normatividad social, distintos modos de convivencia, distintos modos de trato interpersonal, distintos modos de reconocimiento del Otro, todos susceptibles de ser asociados a distintas trayectorias educativas y, así, a distintas culturas. En un alarde de relativismo podríamos aceptar que, en México, hay distintos niveles de cultura, de educación y de riqueza económica, pero los menos cultos, los menos educados y los más pobres son, en su inmensa mayoría, de piel obscura.

La historia de las élites mexicanas y la historia del aparato económico en México controlado por esas élites, se han encargado de convertir a los cuerpos humanos de los más débiles, de los más pobres, y de los menos educados, en signos inamovibles de las condiciones de debilidad, de pobreza y de ignorancia, y sobre todo, en signos inamovibles de la necesidad, para esas élites, de perpetuar esas mismas condiciones.

De acuerdo con Ramales Osorio (2010), en 2008, un diez por ciento de las familias mexicanas concentró el 36.6 por ciento del ingreso trimestral de ese año. Sin embargo, Jusidman (2009: 190) subraya que detrás de las muy fuertes diferencias en la concentración de la riqueza, la desigualdad en México está enraizada en los atributos personales, relacionales y estructurales, 'los cuales determinan las posibilidades de las personas de capturar y retener recursos e ingresos a lo largo de su vida' (Jusidman, 2009: 190).

\section{Objetivos}

Aunque la palabra 'casta', en el sentido de 'raza' o de 'mezcla de razas', ha desaparecido del léxico empleado en las conversaciones cotidianas del México actual, la doble semántica impresa sobre el significado de esa palabra durante la 
Colonia, ha mantenido su vigencia, la cual ha estado, seguramente, cubierta por otros conceptos.

La ausencia de las palabras 'casta' y 'raza', no ha borrado las maneras del trato acordado por los más blancos, a los más obscuros, ni las maneras del trato que estos últimos otorgan a los primeros. Podemos ver esas maneras de trato como formas de civilidad diferenciales y, así, como ambiguos mecanismos sociales de simultánea inclusión-exclusión (White, 2006).

Este trabajo busca apoyarse en el concepto de Civilidad ofrecido por Norbert Elias (1987), para argumentar que ese mismo concepto puede permitir develar algunos de los aspectos de la desarticulación del entramado y del orden social, que históricamente ha estado implicado debajo de la desigualdad económica en México.

A través del concepto eliasiano de Civilidad, podemos acercarnos a la identificación de algunos de los procesos que han estado implicados en ese otro proceso, mucho más amplio, que es el proceso civilizatorio mexicano. El proceso civilizatorio en Europa desembocó en civilidades relativamente uniformes, aunque con fuertes matices nacionales. En México, el proceso civilizatorio que debió haber empezado con la Conquista y con la Colonia, nunca terminó de empezar. La Conquista y la Colonia crearon —al menos - dos grandes civilidades, por un lado, la civilidad de los conquistadores y la de los criollos, y por otro lado, la civilidad de los indios, la cual debía servir de enlace con el mundo español y criollo. Entre ambas civilidades, de manera espontánea, la Conquista y la Colonia permitieron el surgimiento de una multitud de civilidades, sin definiciones explícitas y encerradas en ellas mismas. Esas civilidades informes estarían implicadas en las maneras de trato de todos aquellos que nebulosamente quedaron, también nebulosamente, recluidos dentro de las castas.

Para Norbert Elias, la Civilidad implicada en el proceso de civilización, surgiría como parte del proceso de incorporación de las clases sociales bajas, a las clases sociales altas, y ese surgimiento sería visible en los cambios en los patrones del comportamiento interpersonal experimentados, en Europa, en la transición del Feudalismo Medieval al Renacimiento. En México, como en otros países de América Latina, esa incorporación no ha terminado de empezar, y en México, como en otros países de América Latina, aún es vigente la doble civilidad implicada en la separación entre 'los más blancos', y 'los más obscuros', doble civilidad que encuentra sus raíces en las castas de la Colonia. Sustentados en un poder social y económico históricamente heredado, los primeros han reforzado los obstáculos históricamente ya instalados en contra de esa incorporación.

Seguramente que en Europa, la transición del Medioevo al Renacimiento ofreció una separación análoga a la arriba señalada, la cual habría de diluirse o de deformarse, no obstante, a lo largo de los siglos que siguieron a esa misma transición, no olvidemos que Alessandro de Medici (1510-1538), Duque de Florencia, conocido también como Il Moro, era de ascendencia africana.

En México, como en muchos otros países de América Latina, la sociedad estaba y sigue estando, dividida por los colores de la piel. 
Este trabajo constituye una integración conceptual. En el anterior sentido, el método en él empleado coincide con los resultados de la investigación acerca del proceso cognoscitivo de integración conceptual (Chiappe, 2000; Ritchie, 2004; Turner and Fouconnier, 1999; Turner and Fouconnier, 1995); coincide con los resultados de la investigación en análisis conceptual (Plunkett, 2011; Yehezkel, 2005) y coincide con los resultados de la aplicación de ese análisis a la comprensión de diferentes problemas (Piedra Guillén, 2007).

En ese contexto, el método empleado en este trabajo es el mismo método que es empleado en el establecimiento de cualquier ilación — trabazón razonable y ordenada de las partes de un discurso- requerida por cualquier integración conceptual (Blair, 2012: 43-46).

El escrito busca señalar que el concepto de Civilidad ofrecido por Elias, puede permitir develar algunos de los aspectos de la desarticulación del entramado y del orden social, entramado y orden social que históricamente han estado implicados en la desigualdad socio-económica en México.

Dicha desarticulación ya ha sido culturalmente advertida. El cine mexicano de los años cuarenta y cincuenta advirtió tal desarticulación. Por ejemplo, la secuela fílmica de Nosotros los Pobres (Rodríguez, 1948), Ustedes los Ricos (Rodríguez, 1948), y Pepe el Toro (Rodríguez, 1952), expresó una conciencia de esa desarticulación y una conciencia de la presencia de cuando menos dos civilidades, una de pobres y otra de ricos, y una de indios y otra de blancos en películas como Janitzio (Navarro, 1936), Tizoc (Rodríguez, 1957) y, de cierta manera, María Candelaria (Fernández, 1943). La conciencia de la posibilidad de otras civilidades, es decir, de las civilidades de las múltiples castas implicadas en el mestizaje, no fue expresada, al parecer, con la misma fuerza.

El objetivo del trabajo no es el de aplicar, en toda su minuciosidad, alguno de los modelos de análisis conceptual resultantes de las investigaciones arriba citadas. Tampoco es el objetivo de este trabajo el exponer el estado de avance de esas investigaciones. El objetivo del trabajo es el de argumentar, sin pretensiones de demostración empírica y/o nomotética, la presencia de distintas civilidades en la convivencia en México.

La presencia de esas distintas civilidades puede ser advertida cuando se viaja, el mismo día, de la Colonia Condesa, en la Delegación Cuauhtémoc de la Ciudad de México, hasta la Colonia San Felipe de Jesús, en la Delegación Gustavo A. Madero, también de la Ciudad de México. Esta última colonia alberga el mercado-tianguis más grande del país, y seguramente uno de los más peligrosos (Cruz Flores A. y Gálvez Vadillo E., 2007).

Mientras que esa presencia podría ser considerada como un sustento empírico de la propuesta de este trabajo y, sobre todo, mientras que esa presencia podría ser considerada como una 'posibilidad práctica' de la propuesta de este trabajo, nosotros preferiríamos ver esa misma presencia como una 'posibilidad conceptual'. De acuerdo con Markus (2008), el significado intensional (con 's') de los conceptos permite manejarlos como expresiones de posibilidades y no como referencias a hechos o realidades (actualities, Markus, K. A., 2008: 66). 
Podemos pensar que la argumentación desarrollada por Norbert Elias (1989) acerca de la civilidad, en su libro El Proceso de Civilización, constituye también una integración conceptual, la cual sería el resultado de un método de integración conceptual y de un método de ilación análogos a los resultados de las investigaciones arriba citadas. Podemos pensar que Elias no indicó, de modo claro y preciso, la metodología empleada en la construcción de su discurso de integración conceptual, ni indicó el método empleado en la ilación de ese discurso. A pesar de ello, algunos autores han advertido puntos de acercamiento entre la perspectiva, fundamentalmente conceptual y fundamentalmente interdisciplinaria, de Koselleck (2012) y la perspectiva de análisis histórico de Elias (Dosse, 1998).

Aunque en su Historia Conceptual Koselleck ofrece criterios de objetividad, sus fundamentos filosóficos son muy cercanos a la hermenéutica de Gadamer (Richter, 1994: 135; Koselleck, 1994). En este contexto, podemos pensar que la posición de Koselleck es más cercana a la búsqueda de la comprensión hermenéutica, que a la búsqueda de la demostración empírica y/o nomotética. La oposición entre comprensión y explicación es central en el trabajo de Dilthey (1951: 193-248), el cual es, para bien o para mal, el esfuerzo más importante de la hermenéutica del siglo XIX (Ferraris, 2002: 132).

Aunque este trabajo es muy cercano a los distintos trabajos históricos basados en el análisis y en la integración conceptual, por sus objetivos, él no puede ser llevado hacia la profundización de todos esos temas, ellos están fuera de los objetivos de este trabajo.

El objetivo de este trabajo no ha sido, tampoco, el ofrecer una propuesta acerca de 'lo mexicano', ni la de tomar una posición respecto de la problemática de 'lo mexicano', en el sentido acordado a ella por los trabajos de Ramos (1951), de Villegas (1960), del mismo Octavio Paz (1956), o de otros (Bartra, 2002; Oriol Anguera y Vargas Arreola, 1983; Serra Rojas, 1994; Valenzuela Arce, 2004). El objetivo del trabajo es, queremos repetirlo, el de argumentar, sin pretensión de una demostración empírica y/o nomotética, la presencia de distintas civilidades en la convivencia en México. La argumentación buscaría señalar que dichas civilidades estarían ligadas a la estructuración social basada en, como habría dicho María Elena Martínez (2008), criterios de 'pureza de sangre' y en 'Ficciones Genealógicas', criterios y 'ficciones' que fueron impresos sobre los habitantes del México colonial, por la misma Corona Española, como lo han puesto en relieve Cope (1994) y la misma Martínez (2008), entre otros (Lewis, 2006: 22-26).

Cierto es que la pretensión fenomenológica de Ramos (1951) o de Villegas (1960) resultó ser frágil (Zirión Quijano, 2009: 42-55), pero debemos ser prudentes respecto de los llamados a expulsar la filosofía del campo de la investigación social interdisciplinaria, $\mathrm{y}$ en este último sentido podemos notar que los trabajos fenomenológicos de Alfred Schütz (Psathas, 2004) o de Aron Gurwitsch (2002) son, hoy día, objeto de estudio en ciencias sociales y en ciencias cognoscitivas (Embree, 2004). 


\section{De Raza y de Castas}

Mientras que la palabra 'casta' significa 'puro' en una de las acepciones ofrecidas por los diccionarios, trasladada al dominio de las reflexiones producidas dentro de las Ciencias del Hombre y dentro de las Ciencias de la Sociedad, la misma palabra nos remite a juegos de significado más complejos.

Los trabajos desarrollados por distintos autores señalan que, ya desde los primeros momentos de la colonización española de América, en la Nueva España, la palabra 'casta' designó 'gente mezclada' (Cope, 1994; Martinez, 2008: 341). Así, el significado asignado a esa palabra, en esa época y en esas latitudes, apuntó en una dirección distinta de la dirección apuntada por el significado atribuido por los ingleses a la palabra 'caste', cuando ellos aplicaban esa palabra al sistema Hindú de diferenciación social, el cual estaba sustentado en grupos sociales endogámicos. De acuerdo con María Elena Martínez (2008), los ingleses tomaron el término 'casta' de los portugueses. Esa autora nos deja pensar que, en la América española, el significado 'gente mezclada' implicado en el concepto español de Casta, significado que estaba implicado, a su vez, en la idea colonial de Sistema de Castas, fue el resultado terminal de la inestabilidad que caracterizó a las relaciones entre los miembros de los diferentes grupos raciales, establecidos y reconocidos como tales por los españoles colonizadores de la Nueva España. En este sentido, la membresía a esos distintos grupos raciales carecía de esa estabilidad o de esa inmovilidad interna, que sólo puede dar el rígido mantenimiento de las reglas de esa misma membresía. Los estudios publicados acerca del tema nos dejan pensar que algunos de los miembros de los tres grupos raciales establecidos en la Nueva España a mediados del siglo XVI — por definición, separados—: españoles, indios y negros, se acomodaban, en parejas, con miembros de grupos raciales distintos a los suyos, por encima de las separaciones establecidas, por definición, entre esos grupos, y por encima de los criterios de membresía y de exclusión de cada grupo racial, quizá en búsqueda de solidaridad, de afecto, o de simple compañía y sexo (Martínez, 2008: 12; 341).

La definición del término 'raza' llegó al Nuevo Mundo con los europeos. Estos últimos llegaron no sólo con esa definición, sino con la capacidad de ejercerla como un instrumento de comprensión y de ordenamiento de ellos mismos y de esos seres que encontraron, porque, en la conquista y en la colonización, desde muy temprano hubo ideas que empujaron a los descubridores, a los conquistadores y a los colonizadores, a advertir una humanidad en los seres encontrados en las nuevas tierras. Los nativos hallados en el Nuevo Mundo no eran considerados como estrictamente animales o como estrictamente bestias. Ellos daban muestras de poseer una humanidad y, sobre todo, daban muestras de poseer una humanidad esencialmente cristiana (Rozat Dupeyron, 2002: 184-193; Rozat Dupeyron, 2001: 253-261; Todorov, 1996: 44-45).

El concepto de Raza que podemos hallar en la Nueva España, llegó con los españoles como un instrumento para el establecimiento de una forma del orden, el cual habría de ser impuesto sobre el universo humano enfrentado, como un 
instrumento de medición de la distancia que los europeos debían guardar respecto de los salvajes, y como una forma de justificación de la enconada búsqueda de la riqueza que los movía.

Si los conquistadores y los colonizadores llegaron a las Américas ya ataviados con adjetivos básicos, como el de 'español' —o, en su caso, el de 'portugués', y más tarde, el de 'inglés'-, ellos llegaron buscando adjudicarse otros adjetivos más, en particular esos adjetivos ligados al poder social, sólo otorgado por la riqueza, razón esencial de tal aventura, riqueza carecida en las tierras de partida.

Sin embargo, en las tierras de partida, la riqueza estaba ligada a la nobleza y esta última estaba ligada a la continuidad de la sangre. En la Europa de la transición de la Edad Media al Renacimiento, y desde mucho antes de esa transición, la nobleza exigía linajes, exigía pureza de vida y de sangre, y exigía, por lo tanto, la acumulación de generaciones, es decir, la acumulación de historias de vidas, y la acumulación de limpieza de sangre.

El concepto de Genealogía había sido constituido, históricamente, como un instrumento de demostración de la valía de la sangre, de la raza y de la nobleza. Si la genealogía sirvió de base al temprano desarrollo del concepto de Raza, como un concepto sustentado en la idea de una 'continuidad de la sangre', estos conceptos no tuvieron el mismo desarrollo a lo largo de Europa. María Elena Martínez (2008: 5354) señala que los conceptos de Noblesse de Sang y de Raza servían de base a la separación social entre Nobles y plebeyos. El enlace establecido por la nobleza francesa entre nobleza y raza, buscaba señalar la superioridad de los primeros sobre los plebeyos, de tal forma que un contacto carnal entre ambos, mancharía y corrompería la sangre noble. Para María Elena Martínez, mientras que los conceptos franceses de Genealogía, de Raza, y de Noblesse de Sang, formaban parte de un 'discurso de "clase"' social, los conceptos españoles de Raza, de Linaje y de Limpieza de Sangre, formaron más bien parte de un 'discurso religioso', aplicado a miembros de 'grupos religiosos y a sus descendientes' (Martinez, 2008: 54). En ese sentido, Martínez (2008: 54) propone que el concepto español de Limpieza de Sangre señalaba la oposición que habría entre la 'sangre limpia' de los cristianos, y las 'sangres polutas' de judíos y musulmanes. Sin embargo, el concepto castellano de Limpieza de Sangre no mantuvo su significado en la Nueva España. Acá, diferentes factores y dinámicas sociales contribuyeron a transformar esa noción y a establecer, en ella, una relación entre 'limpieza' y 'españolidad', una relación que estuvo siempre fuertemente impregnada de ortodoxia religiosa (Martínez, 2008: 2).

Aunque el análisis del problema histórico de la raza en México ha recibido cierta atención (Carrera, 2009; Jackson, 1999; Kamilamba, 2005; Mörner, 1974; Mörner, 1967; Simms, 2008; Treviño Rangel, J. 2008), las respectivas propuestas de Martínez (2008) y de Cope (1994) sobresalen sobre los distintos trabajos publicados sobre ese tema.

Martínez asume una posición teórica que lleva el problema de la raza más allá de los límites de las meras dinámicas de las clases sociales. De acuerdo con una perspectiva que se inscribiría dentro de esos límites, el concepto de Raza vigente en 
una sociedad dada, sería expresión de la dinámica de los intereses de una clase social, para la cual la elaboración de una definición ad hoc de raza, y la aplicación de tal definición, permitiría resguardar y perpetuar su poder. Más allá de una perspectiva como la antes esbozada, para María Elena Martínez el problema de la raza está revestido de una importante dimensión conceptual, ideológica por lo tanto. La raza, en tanto que conjunto de conceptos y en tanto que conjunto de prácticas, está indudablemente ligada, en formas complejas, a distintos entramados de condiciones sociales y económicas, pero también está ligada a esos sistemas de significado y a esas estructuras ideológicas que son inherentes a las condiciones sociales y económicas (Martínez, 2008: 3).

El concepto de Raza vigente en una sociedad dada, las prácticas sociales implicadas por ese concepto y las maneras en las que esas mismas prácticas son ejecutadas, no se mantienen en un estado estático, a-histórico. Él y ellas se transforman, se diluyen e incluso desaparecen, para después reaparecer, arropado él y arropadas ellas, con otros vestidos conceptuales inscritos en nuevos sistemas de significado y en nuevas estructuras ideológicas, ambos ligados a nuevos acomodos de los aparatos de poder social y económico, imperantes en esa misma sociedad.

Ubicada dentro de una posición teórica de Análisis Genealógico, inspirada primero en Nietszche y luego en Cornel West, para María Elena Martínez (2008), la comprensión de un concepto dado - Casta en este caso - vigente en un momento histórico dado, en una sociedad dada, requiere el develado del trayecto histórico de ese concepto; requiere el develado de los conceptos de los cuales él se ha desprendido, y requiere el develado de las relaciones entre todos esos conceptos, y los distintos sistemas de significado, estructuras ideológicas, condiciones socioeconómicas, y aparatos de poder social y económico, vigentes a lo largo del trayecto histórico de ese concepto. Así, para María Elena Martínez, la comprensión de un concepto dado requiere un Análisis Genealógico (Martínez, 2008: 3-4).

Sin pérdida alguna de poderío analítico, Douglas Cope (1994: 49-52; 57) adopta una posición más pragmática, más funcional. Para este autor el concepto de Raza no es auto-evidente. Llevado al terrero de la biología, el concepto de Raza aplicado a los seres humanos tanto en algunos discursos ordinarios, como en algunos discursos académicos, fracasa en el cumplimiento de la estructura jerárquica conceptual básica de esa disciplina: la familia comprende al género y el género comprende a la especie. Si bien es cierto que las diferencias genéticas están detrás de la determinación de las diferencias en la apariencia física, sería muy atrevido afirmar que los factores genéticos inequívocamente separan a los seres humanos en distintas categorías y, en este sentido, cualquier línea de separación racial sería no sólo arbitraria, sino socialmente construida. Así, Douglas Cope retoma esas posiciones sostenidas dentro de la biología, de acuerdo con las cuales ese concepto de Raza tendría poco o ningún sustento científico (Cope, 1994: 50).

Empero, con la anterior conclusión, Cope no da por terminado el análisis de los problemas subyacentes al concepto de Raza. El carácter social y arbitrario de ese concepto señala, ya, el siguiente paso de ese mismo análisis. Ese carácter y esa arbitrariedad exigen identificar a ése o a ésos que han construido ese concepto; 
exigen también identificar a ésos que lo han aplicado; exigen identificar a ésos sobre quienes dicho concepto ha sido aplicado; y exigen identificar las funciones sociales que se han cumplido con su aplicación.

Para Cope (1994: 57), los conquistadores y los colonizadores definieron su concepto de Raza más sobre criterios funcionales que sobre criterios lógicos; más sobre criterios pragmáticos que sobre criterios teóricos. Así, los conquistadores y los colonizadores basaron su definición de raza, más en criterios de ideales 'somáticos' (Cope, 1994: 51; Hoetink, 1967; Giovanneti, 2004), que en características comprobadamente permanentes, comprobación y permanencia que, en esa época, habrían sido difícilmente pensables.

El Universo humano y social de la Nueva España de los primero años de la Conquista y de la Colonización quedó claramente ordenado y, así, claramente entendido, sobre la base de una separación racial entre españoles e indios, la cual se sustentó en ideales de lo que sería una 'imagen somática' aceptable, la cual sería, a su vez, convertida en norma de lo 'somática' y socialmente aceptable. Las iniciales diferencias físicas y las, también iniciales, diferencias culturales y religiosas, permitieron a los europeos entender un mundo el cual empezaba a ser suyo por medio del ejercicio de decretos cuyos contenidos habían sido creados por ellos mismos, sobre la base de su propio poder, el cual fue, en parte, también de su propia creación. La Corona Española ordenó ese mundo en términos de dos entidades sociales unidas, pero separadas: La República de Españoles, y la República de Indios. Es decir, la Corona Española ordenó ese mundo en términos de dos 'sustancias públicas' distintas, relativas a dos comunidades humanas y espirituales —-sociales y culturales - también distintas, apegadas a leyes 'buenas' y 'justas', y guiadas por un solo gobierno 'bueno' y 'justo', el de la Corona (Levaggi, 2001; Enciso Contreras, 1995).

Sin embargo, para la segunda mitad del siglo XVI ya habían aparecido, entre esos dos universos claramente identificables, los hijos de las distintas mezclas, los hijos de los distintos mestizajes posibles entre los tres grupos raciales reconocibles en la Nueva España. Esos hijos fueron seres de difícil identificación dentro de la anterior división, y de más difícil comprensión dentro de tal ordenamiento. Para esos hijos no hubo 'República', ellos no la alcanzaron, no porque ellos no hubieran sido pensados desde los inicios de la Colonia (Bazave Benítez, 1992), sino porque no se advirtió, en ellos, el anhelo del orden social que había sido idealizado por la Corona para los habitantes de las Tierras Americanas y, además, porque ellos no pudieron ser colocados en ninguna de las 'sustancias públicas' establecidas.

Aunque, para Cope (1994: 14-15), la aparición del término 'mestizo' en la Nueva España, a mediados del siglo XVI, sirvió más para hacer referencia a individuos carentes de lugar en cualquiera de las dos únicas 'Repúblicas', que para hacer referencia a un estatuto racial específico, por encima de esa carencia de adscripción social y política, prevalecieron el ideal y la norma somática, los cuales sirvieron, a las élites, de instrumento para señalar a los miembros de las castas. Sin embargo, ellos no necesariamente fueron señalados como ejemplos de un grupo racial dado, porque con la mezcla, las características físicas, morfológicas, 
somáticas o corporales se volvieron difusas, ambiguas y polivalentes. Ellos fueron señalados como ejemplos de todo lo que pudiera constituir una amenaza a la estabilidad de la separación entre españoles e indios (Cope, 1994: 15).

Dentro de esa perspectiva, el mestizaje fue, desde el principio, la inevitable esencia y fuente de esa amenaza. La Corona ofreció, como cura o sanación para tal amenaza, el cristiano sacramento del matrimonio (Bazave Benítez, 1992), pero este último ni frenó el nacimiento de mestizos, ni redimió a estos últimos de esa mancha esencial que era inherente a la indignidad de la mezcla, ni mucho menos, los redimió de la mancha implicada en el ser producto de una mezcla no purificada por medio de ese sacramento.

Así, desde su aparición, los mestizajes, es decir, las castas, carecieron de comunidad, de historia, de universo político al cual replegarse y sobre todo, carecieron de identidad digna. Además, todo ello también les fue negado (Cope, 1994: 16).

Desde muy temprano en el siglo XVI, la Corona Española estableció un sistema de clasificación de mezclas raciales: el Sistema de Castas (Cope, 1994; Jackson, 1999), pero ese sistema nunca alcanzó —ni pretendió hacerlo — la dimensión de una 'República'.

La legislación impuesta sobre los miembros de las castas, en particular sobre los negros y sobre los mulatos, fue más de carácter restrictivo, que de carácter 'distributivo', por ejemplo, la Corona Española prohibió a los miembros de las castas habitar en las comunidades indias. Si la medida buscaba fortalecer la separación entre indios y españoles, una de sus consecuencias no pensadas fue la de confinar a los miembros de las castas al universo físico y social español, un universo en el cual las castas carecían de lugar y en el cual, además, ellas eran despreciadas (Cope, 1994: 16-17). La justicia había sido pensada ya, por el fraile Juan Zapata y Sandoval, en la Nueva España de principios del siglo XVII, como una justicia distributiva (Ramírez Trejo, 2005).

Así, debajo de la deslumbrante 'Ciudad de los Palacios', construida dentro de la traza de la ciudad de México, y debajo de los palacios construidos dentro de las trazas de las principales ciudades españolas de la Nueva España, se desplegaba la desordenada e inestable vitalidad mestiza de los miembros de las castas, es decir, la desordenada e inestable vitalidad de los pobres, la mayor parte de ellos, hijos de la mezcla de todas las razas, hermanados no por sus membresías al Sistema de Castas, ni por una pobreza compartida, sino por esa diversidad de estilos de vida que sólo puede surgir de una exclusión y de un resentimiento social, exclusión y resentimiento que eran expresados en forma de desdén por los órdenes establecidos por las élites en el poder (Cope, 1994: 49), élites que eran la fuente no sólo de las infamantes clasificaciones de las mezclas raciales, sino de las mezclas mismas.

Ese desdén era acompañado de un anhelo -emoción esencialmente psicológica - paradójico de acercarse a las mismas élites que habían definido, impuesto y engendrado la mancha poseída. Ese anhelo también era paradójico porque él implicaba el rechazo de sí mismo —o el rechazo de una dimensión de sí mismo-, y el rechazo de los iguales, algunos de los cuales podían muy bien ser 
tomados — dependiendo de los jueces y dependiendo de las características somáticas - por españoles, por criollos, o por indios. Los casos documentados por Cope (1994), por Martínez (2008), y por Jackson, 1999) permiten advertir las frecuentes dificultades, enfrentadas por los españoles desde los primeros tiempos de la Colonia, para ubicar con precisión a una persona, en alguna de las múltiples categorías de mestizaje, es decir, en alguna de las múltiples expresiones de las castas (Katzew, 2004).

Así, para los miembros de las castas, la cuestión del 'no-ser-algo' — la cual no era enfrentada por los que sí eran 'algo', es decir, por los hijos-d'algos, por los hidalgos españoles de sangre cristiana inmaculada - y sobre todo, la cuestión de no parecerlo o de parecerlo, se convirtió en una ventaja. Los miembros de las castas podían aparentar y pretender ser lo que el observador creía que eran, según sus conveniencias y según las ventajas —o desventajas - de la coyuntura. Dentro de esta posibilidad de poder ir y venir entre el ser y el aparentar, había dos parámetros sociales y humanos de referencia, el superior al cual se podría parecer o con el cual se podría establecer una mimesis, sobre la base de conceptos arbitrarios sobre lo 'superior somático', y el inferior somático.

De acuerdo con Douglas Cope (1994: 4), los españoles difundieron con éxito la idea de una jerarquía racial, el Sistema de Castas, dentro de la cual, el nivel superior era ocupado por ellos mismos y, a partir de ahí, esa jerarquía desplegaba múltiples niveles antes de alcanzar sus niveles más bajos, el de los indios y el de los descendientes de africanos. Aunque las castas ocupaban el plano medio, esta 'medianía' no correspondía a tal. La carencia de una identidad clara, sirvió para rebajar las castas si no hasta el nivel más bajo, sí hasta el nivel más despreciado, un nivel inferior incluso al acordado a los indios.

Esa jerarquía racial estaba acompañada de la suposición de una autoconciencia del lugar ocupado, dentro de esa jerarquía, por cada grupo racial, y de la suposición de una autoconciencia del lugar de superioridad ocupado por los españoles. El logro de la implantación de estas suposiciones debía servir de base para la conversión de los 'grupos subordinados', en sus propios opresores, y debía igualmente servir para mantener la hegemonía de los ibéricos. Con este mecanismo implantado, debajo del nivel más alto de la estructura jerárquica, el cual se hallaba protegido por su propia definición de superioridad, se desplegaba una lucha individualizada dentro de cada uno de los distintos niveles inferiores de esa misma estructura y entre esos niveles. Carente de compromisos de igualdad, esa lucha tenía entre sus objetivos más importantes el de ascender a los niveles de los grupos de 'piel más pálida'. En esa lucha, protagonizada generalmente por los miembros de las castas, el arma corriente era el escarnio de lo inferior. Qué mejor manera, para las élites hegemónicas, de salvaguardarse a sí mismas, y qué mejor manera, para las mismas élites, de protegerse a sí mismas del desgaste implicado en cualquier confrontación, que convirtiendo a las clases inferiores en sus propios opresores. Respecto de todo lo anterior, Douglas Cope añade: 'Para confirmación de esas afirmaciones uno sólo necesita mirar la actual estructura socioeconómica de la sociedad urbana' (Cope, 1994: 4). 


\section{Las Castas Veladas del México Actual y la Civilidad}

Lo trascendente del encuentro entre españoles y autóctonos mesoamericanos, en los inicios de la Conquista y de la Colonización misma, es decir, lo trascendente del hallarse contra-a-contra, cara-a-cara, españoles y autóctonos, en esos inicios, no fue ese encuentro, sino el nunca lograr iniciar una integración; sino el nunca lograr esbozar una vía que permitiera dignidades equiparables, las cuales serían ejercidas en el seno de la aceptación abierta, de las diferencias de todas las partes efectivamente implicadas en ese encuentro primigenio.

El encuentro entre españoles y autóctonos mesoamericanos fue, más bien, el desencuentro de dos cosmovisiones (Wolf, 1967: 203), y si bien, desde los inicios de la Conquista y de la Colonia se enfatizó ese desencuentro, paradójica o contradictoriamente, también desde los principios de la Conquista y de la Colonia se propuso al sacramento del matrimonio entre españoles e indios, como una vía para su acercamiento y para su posible integración (Bazave Benítez, 1992: 17-19), mientras que se concebía a la Nueva España como integrada por dos distintas y separadas Repúblicas, es decir, por dos ‘sustancias públicas' distintas y separadas, la de los españoles y la de los indios.

La propuesta del cristiano matrimonio encontró que el camino hacia la satisfacción de la carne fue, con mayor frecuencia, más corto que el camino hacia cumplimiento de ese sacramento, y el nacimiento de mestizos fuera de dicha bendición no sólo hizo más difícil la integración esperada como resultado del matrimonio entre españoles e indios, sino que introdujo un personaje más dentro de ese desencuentro: las castas, es decir, los productos de todas las formas de esos mestizajes ilegítimos que eran posibles desde los inicios de la Nueva España (Bazave Benítez, 1992; Cope, 1994).

Con la Independencia, es decir, con el cambio del estatuto jurídico de esa doble 'sustancia pública' que conformaba a la Nueva España: la República de Españoles y la República de Indios, se diluyó el énfasis del desencuentro entre españoles e indios. Sin embargo, esa dilución fue, de hecho, una paradoja más, una contradicción más que habría de perpetuarse de manera casi imperceptible.

El desencuentro entre españoles - y sus paralelos criollos- e indígenas autóctonos mesoamericanos, se diluyó en una imperceptible paradoja, en una imperceptible contradicción, a partir del momento en el que, por decreto, se estableció un 'ciudadano' y se negó toda diferencia entre 'ciudadanos' de ascendencia europea, y 'ciudadanos' de ascendencia indígena. En esta paradoja se desindianizó al indio y se le redimió por la vía de su desaparición (Bonfil Batalla, 2005), para subrayar lo europeo como el ideal a perseguir.

No obstante, con esa 'desindianización’ y con esa 'redención’ por la vía de la desaparición', el indio quedó amarrado, como tal, a la base de esa paradoja, porque ya constituido en ciudadano, él continuó amarrado a una pobreza y a una injusticia que, ahora, le es histórica y que, además, lo desconoce en su singularidad étnica, porque tal singularidad desapareció con el estatuto de 'ciudadano'. 
En medio de ese desencuentro y, también, debajo de él, yace actualmente la continuación histórica de las castas, es decir, un mexicano que no es ni español, ni criollo, ni indio, un mexicano intersticial que será representado como el mexicano 'pelado' (Yañez, 1992: XVIII-XXXII), como el mexicano 'lépero' (Prieto Hernández, 2001), como el mexicano del 'bajo pueblo' (Prieto, 2009: 582), y como el mexicano 'naco' que nunca tuvo que ser ni 'desindianizado', ni 'redimido', porque siendo mestizo nació desindianizado y nació redimido, y porque siendo mestizo se inscribió en una historia de exclusión, las cuales - historia y exclusión- alentaron el cultivo del desdén por los órdenes decretados por las élites en el poder, alentaron la cultura del desdén por todos los órdenes sociales y, simultáneamente, permitieron en ese mismo mexicano la utilización oportunista de todos esos mismos órdenes.

Desde sus inicios, las castas fueron impuras, desde los inicios de la Colonia, el universo de los productos de las múltiples formas de mestizaje fue impuro porque en él se congregaron, también, indios rebeldes a la vida en sus propias comunidades, negros libertos, y europeos fracasados en el logro de la riqueza perseguida, descendientes pobres de conquistadores también pobres, en fin, españoles y criollos carentes de esas relaciones que son indispensables para poder ubicarse ‘donde sí hay’ la anhelada riqueza fácil y rápida (Wolf, 1967: 204-205).

Los niveles más altos de la sociedad colonial estaban ocupados no sólo por los ricos, sino por los dotados de poderes gubernamentales y administrativos, todos ellos generalmente europeos. Alrededor de sí mismos, ellos tejieron una sociedad de relaciones fuera de la cual todo era casi imposible (Wolf, 1967: 207-208).

Sin embargo, esa cerrada sociedad de relaciones de élites era permeable. De acuerdo con Wolf (1967: 208), el mantenimiento de una sociedad de relaciones y de imposibilidad, requiere transacciones que necesariamente van a inscribirse en la ilegalidad, o muy cerca de ella. Esas transacciones, en sus partes más mecánicas, eran realizadas por los excluidos, es decir, por los miembros de ese muy diversificado universo humano que era el universo de las castas. Esos miembros habían sido, históricamente, impregnados de un sentimiento de desdén respecto de los órdenes establecidos.

De acuerdo con Wolf (1967: 209), la capacidad de sobrevivencia de los miembros de ese universo humano no reposó en el cultivo de un 'equipaje cultural', ni en su 'adhesión a las normas de la civilización', sino en lo que hoy podríamos ver como un mimetismo oportunista, carente de lealtades y de normas. Para Wolf, el mestizo es, en el anterior sentido, la antítesis del indio, porque mientras que este último se mantiene apegado al lugar y a las normatividades que el europeo y el criollo le asignaron, el mestizo ha pulido el difícil arte del aparentar complacer a estos últimos, para estar siempre cerca de la 'gente de razón', de la 'gente bien', porque ellos poseen riqueza y poder.

Para el mestizo aludido por Wolf, y sobre todo, para el mestizo del México de hoy, la riqueza y el poder son sólo medios de auto-afirmación frente a una sociedad que lo niega. Él va a evaluar su nivel de progreso en términos de la riqueza y del poder concentrados en él mismo. Él no va a evaluar su progreso a partir de la 
adquisición de nuevas y menos agresivas maneras de trato hacia el Otro, ni mucho menos va a evaluar su progreso personal a partir de la cultura adquirida, en el sentido alemán del término. Él no se va a sentar a la mesa, para reflexionar y comparar sus modales de su época de pobre, con sus modales de su momento de rico y poderoso, para así exclamar: 'Cuánto hemos progresado en comparación con esos niveles de desarrollo!’ (Elias, 1987: 113).

Para Wolf, el mestizo, es decir, el miembro de las castas y su heredero, es un Buscador de Poder. Él es producto de un mundo que, para él con mayor énfasis, ha carecido de órdenes y de restricciones insalvables. Para Wolf, el miembro de las castas y su heredero, está acostumbrado, por lo tanto, a recurrir a cualquier medio para conseguir el poder, está acostumbrado a poner en marcha la agresión y el engaño para afirmarse ante quien sea necesario (Wolf, 1967: 209-211). Él no pertenece a clase social alguna, él es instancia individualizada de una condición humana, y no de una membresía social, él es un tipo de individuo y no el ejemplo o la muestra de una clase social. La sociedad, la comunidad, el grupo social sólo tienen existencia para el individuo, y sólo la tienen como instrumentos de los fines perseguidos por este último. El individuo no existe ni para la sociedad, ni para la comunidad ni para el grupo, él existe sólo para sí mismo (Wolf, 1967: 210).

El discurso analítico sostenido por Wolf acerca del miembro de las castas, acerca del mestizo, amplía sus horizontes históricos más allá de los confines del período de la Colonia, y se permea en otros discursos, también analíticos, sostenidos en épocas distintas, acerca de los avatares de esa membresía, acerca de los avatares de esa misma herencia: el 'lépero', el 'pelado', el 'naco'.

A mediados del siglo XIX, Guillermo Prieto ubicaba al lépero como ése que '...para caracterizarse de pura sangre, ha de ser mestizo, bastardo, adulterino, sacrílego y travieso...' (Prieto, 2009: 285). El lépero es flojo, estafador, rastrero, amigo de la vagancia y del juego, finge sumisión para tornarse impredeciblemente violento y asesino, detesta la deshonestidad en los suyos, hacia quienes él es, paradójicamente, honesto y desinteresado (Prieto, 2009: 286-289).

A mediados del siglo XX, en un Estudio Preliminar a la obra de José Joaquín Fernández de Lizardi El Pensador Méxicano, Agustín Yáñez abre lo que para él sería la 'Ecuación Psicológica del "Pelado"' (Yáñez, 1992: XXV-XXVII). El 'pelado' es el mexicano en estado de naturaleza, el tipo representativo del mexicano mestizo. Aunque predomina en él la sangre indígena, del español trae el cristianismo. En él se integran la soberbia, la predisposición picaresca, la inclinación al vagabundeo, el anarquismo, la dignidad personal exacerbada, y la desconfianza en el otro y en sí mismo. El 'pelado', según Yáñez, quiere ser él solo, sin vocaciones múltiples, con capacidad para seguir distintos reclamos del destino, carece de disciplina y sólo se esfuerza para buscar la satisfacción de sus necesidades perentorias. El 'pelado' dice Yáñez, no tiene orden, no es gente de orden, y ya en el desenfreno, alcanza una crueldad que es implacable, porque es histórica.

Avatares de los miembros de las castas, el 'lépero' y el 'pelado' son también los precursores del mexicano 'naco' contemporáneo. A mediados de los años setenta del siglo ahora pasado, Monsivais (2010) retrataba al 'naco' como ese mexicano 
'desplazado' que no alcanza una concreción por falta de urbanidad y de buenas maneras: 'Sin sociedad no hay personalización'. Para Monsivais, la noción de Naco alcanza su mayor nivel de integración conceptual a partir de los años cincuenta. A partir de ese momento, el término 'naquiza' sirve para expresar el más agudo de los desprecios por dos de los más importantes componentes de la realidad humana de México: el mestizo y el indio. Por la vía del término 'naquiza', el término 'naco' termina por ser aplicable tanto a indígenas como a mestizos, pero serán siempre los primeros los más despreciados. De manera subrepticia, esos términos han terminado por integrar la historia de la desigualdad abierta, en México, por la Conquista y por la Colonia.

El 'naco' presentado por Monsivais, actualiza la historia de la desconfianza y del recelo sostenidos por el mestizo miembro de las castas, respecto de los órdenes sociales, y también actualiza la búsqueda por la ascensión social y económica a cualquier precio, perseguida por el mestizo, Buscador de Poder, presentado por Wolf.

La familia y el compadrazgo son los más fuertes soportes sociales del 'naco' de Monsivais: '¡El naco en México! Aquel que no niega desde su apariencia su adhesión a la Raza de Bronce...' (Monsivais, 2010). El 'naco' presentado por Monsivais, no sólo está marcado por el color de su piel, sino por su carencia de educación y de 'maneras'. Él es ‘feo e insolente, sin gracia ni atractivo, irredimible, imagen inferiorizada de un país menor, lleno de complejos, resentido, vulgar, grueso...' (Monsivais, 2010).

Los 'léperos', los 'pelados' y los 'nacos' son, así, las actualizaciones del mexicano intersticial, del mexicano mestizo heredero de las castas de la Colonia. El 'lépero’, el ‘pelado', el ‘naco’ integran las castas veladas del México actual.

El desdén por los órdenes sociales, desdén que atraviesa a todos ellos, los unirá en un rasgo que les será históricamente común, y que los alejará de la capacidad de advertir la existencia del Otro en relación con la existencia de sí mismo. Ese mismo desdén los alejará de la capacidad de respetar al Otro - Respeto, Respecto, del latín: re-spicere. De: re: atrás, hacia atrás + spicere, specere: mirar (Gómez de Silva, 1988)—; los alejará de poder alcanzar esa capacidad psicosocial consistente en poder 'contemplar hacia atrás' las consecuencias de las acciones propias sobre los otros.

Más allá de esos humanos que les son cercanos, más allá de esos humanos que son sus 'aparceros', como diría Guillermo Prieto (2009: 286), los miembros de las castas, antiguas y actuales, no respetan a nadie y recelan de todos y, así, en ellos no cabe civilidad alguna.

Si las maneras del comportamiento respecto del Otro y de los Otros, y los conceptos que 'condensan' tales maneras, expresan las formas de autoconciencia alcanzadas por los grupos sociales que practican tales maneras y que emplean tales conceptos (Elias, 1987: 108), entonces podemos suponer que en las castas veladas del México actual, tales maneras son limitadas en número y son aplicables en un número relativamente reducido de ámbitos: la familia, las amistades, y las personas 
con quienes el trabajo y las actividades económicas, hacen ineludibles los encuentros.

En esos ámbitos, las maneras del trato hacia el Otro o hacia los Otros, mantienen fuertes relaciones con las figuras de autoridad que son internas a cada ámbito. El respeto diferencial hacia los padres, es decir, hacia el padre y hacia la madre; el respeto también diferencial hacia los hermanos, es decir, hacia hermanos y hermanas; el respeto hacia los familiares: abuelos, tíos, primos, todos ellos estructurados en términos de jerarquías de valor afectivo; el respeto —impregnado de desprecio - hacia los sirvientes, siempre presentes en la familia mexicana; etc., son todos definidos y vigilados por las figuras de autoridad del ámbito familiar. Díaz Guerrero (1974) develó el lugar de autoridad acordado por la mujer al padre de familia, y el lugar de sumisión acordado por la mujer a ella misma. Son interesantes las propuestas de Robichaux (2002), acerca de lo que sería la sociogénesis de la familia mesoamericana de origen rural. En el mismo sentido, es interesante el trabajo de Arriagada (2007), acerca de las actuales transformaciones estructurales de la familia latinoamericana.

Fuera del ámbito familiar, las maneras del trato hacia el Otro se reducen en número y se vuelven más escuetas. Así, fuera de las empresas familiares, las cuales se rigen por estructuras de autoridad propias a la familia, en este caso, propias a la familia mexicana (Vilas, 1996; Lomnitz y Pérez Lizaur, 2006), el respeto hacia las autoridades laborales, el respeto hacia los empleados, el respeto hacia el proveedor comercial, el respeto hacia el cliente, y en general, el respeto al Otro desconocido y no-familiar, se vuelve esquemático, la convivencia se simplifica pero no se abrevia, los silencios se alargan mientras las actividades aparentan concentrarse en los objetivos y características de las tareas, pero la empatía es mínima y, así, espaciados por silencios, los escasos sentimientos por ese Otro desconocido, se expresan de manera breve, sin matices psicológicos. Se abre aquí un terreno esencialmente maniqueo, carente de matices: o es amigo o es enemigo, o se somete o se le extermina, o es placer o es dolor, o son personas buenas o son personas malas (Elias, 1987: 108).

Recordemos, aquí, que un buen número de los preceptos contenidos en los libros de buenos modales aparecidos entre el siglo XV y el siglo XVI, en particular el libro de Erasmo de Rotterdam De Civilitas Morum Puerilium, publicado en 1530, eran preceptos destinados a guiar el comportamiento en público.

Más allá de esos ámbitos, el de la familia y el de la vida económica, las condiciones que podrían dar lugar el surgimiento de las maneras de trato del Otro se vuelven nebulosas. Los espacios públicos, necesariamente regulados por distintas formas de normatividad social, se vuelven extensiones de los ámbitos personales y familiares. A finales del siglo XIX, el literato mexicano, José Tomás de Cuéllar (1892: 150-159), reprobaba el uso que se hacía de las calles y de las banquetas de la Ciudad de México. En ellas, la gente comerciaba, pero también dormía, comía, se aseaba y defecaba sin pudor alguno.

Desconocemos, no obstante, cuál es el concepto o cuáles son los conceptos actuales que 'condensan' las maneras de trato hacia el Otro, e igualmente 
desconocemos si esos conceptos se aplican, de manera generalizada, a todos los ámbitos, o si cada uno de ellos es aplicado a un ámbito específico al cual le correspondería de manera diferenciada.

Podemos reconocer algunos de los términos empleados, actualmente en México, para hablar de las maneras de trato hacia el Otro y hacia los Otros: 'decencia', 'amabilidad', 'respeto', 'cultura', 'educación'. Se trata de términos que hacen referencia a maneras no-agresivas de trato. Las personas que despliegan tales maneras de trato, son calificadas de 'decentes', 'amables', 'respetuosas', 'cultas', 'educadas'. Ellas son 'gente bien', 'gente de razón', 'gente fina'. Quienes despliegan maneras agresivas de trato hacia el Otro, son calificados de 'nacos', de 'pelados', o de 'corrientes'. Así, se cumpla o no se cumpla la condición, el trato rudo, 'descortés' y agresivo es generalmente atribuido al 'lépero', al 'pelado', al 'naco'. Algunos informantes que hemos entrevistado para otro estudio, habitantes de una zona semi-rural del Estado Veracruz, en México, con una educación primaria no terminada, han señalado que: '...cuando uno es amable, educado, (los otros) terminan tomándolo a uno por su 'tonto.' No voy a permitir que nadie se quiera pasar de listo conmigo'. En un mundo poblado de enemigos individualizados, la civilidad no es recomendable y, así, no tiene sentido aprenderla.

Si las maneras de trato hacia el Otro y hacia los Otros expresan la autoconciencia de quienes las practican, ellas también expresan la conciencia alcanzada por estos últimos, acerca de quienes son objeto de esas maneras de trato, y esas maneras y estas conciencias no emergen, dentro de una sociedad, como algo aislado, ellas y ellos forman parte de lo transmitido por una sociedad, ellas y ellos forman parte de ese proceso dinámico que, bajo ciertas condiciones, da continuidad a esa sociedad. Esas maneras y esos conocimientos corresponden a una estructura social absolutamente determinada (Elias, 1987: 114; 123-124).

Sin embargo, podemos pensar que los modelos generales de las maneras de trato hacia el Otro, que sirven de base a la convivencia humana y social de las familias mexicanas de mayores ingresos trimestrales promedio, ubicadas a partir del Decil VI hasta el Decil X, de la Tabla correspondiente al Ingreso Total Corriente Promedio Trimestral (INEGI, 2011), no son los mismos modelos generales de trato hacia el Otro, que sirven de base a la convivencia de las familias con menos ingresos trimestrales promedio, ubicadas en los primeros Deciles. Hay un abismo insalvable entre el hombre más rico del mundo según FORBES, y las familias ubicadas en esos Deciles.

Para Juan Díaz Covarrubias, escritor mexicano del Siglo XIX, 'México es un país eminentemente republicano por su forma de gobierno, y sin embargo tal vez ni en la monarquía más absoluta de Europa, está establecida de una manera tan notable la distinción de las clases. La aristocracia, la clase media y el pueblo. Pues bien, cada una de ellas tiene su fisonomía, sus costumbres particulares, nunca se mezclan, por el contrario, están separadas por el odio...'

Seguramente que Europa ofrecía ese mismo divorcio, pero en México, como en muchos otros países de América Latina, la sociedad estaba y sigue estando, dividida 
por los colores de la piel. En México, el color de la piel es el más importante elemento de la semiótica de las diferencias socio-económicas.

\section{Conclusión}

La eliminación de la palabra 'casta', en su sentido de 'raza', y la eliminación de esta última palabra, en México, eliminaciones abiertamente iniciadas a mediados del siglo XIX y consolidadas a principios del siglo XX, fueron en realidad una substitución. Las palabras 'casta' y 'raza' fueron remplazadas por las palabras 'cultura', 'etnia', 'pueblo’ u otras. Los de piel más blanca y los más altos tendrían cultura, educación, riqueza y, por supuesto, civilidad, pero carecerían de etnia. Históricamente, ellos han pasado por ser españolados, acriollados, afrancesados u otras interpretaciones del ser de piel pálida, en la tierra mexicana de indios, de negros y de mestizos morenos o de piel café.

Los de piel más obscura, es decir, la inmensa mayoría de los mexicanos, carecerían de riqueza, de educación y de cultura. Sin saberlo y en contra de su voluntad, ellos serían la 'indiada', la 'leperada', la 'peladez', la 'plebe', la 'naquiza', mientras que simultáneamente habría una auténtica 'indiada' que incluso sería distinta y Otra.

Para Norbert Elias, la Civilidad implicada en el proceso de civilización, surgiría como parte del proceso de incorporación de las clases sociales bajas, a las clases sociales altas, y ese surgimiento sería visible en los cambios en los patrones del comportamiento interpersonal experimentados, en Europa, en la transición del Feudalismo Medieval al Renacimiento. En México, como en otros países de América Latina, esa incorporación no ha terminado de empezar, y en México, como en otros países de América Latina, aún es vigente la doble civilidad implicada en la separación entre 'los más blancos', y 'los más obscuros', doble civilidad que encuentra sus raíces en las castas de la Colonia. Sustentados en un poder social y económico históricamente heredado, los primeros han reforzado los obstáculos históricamente ya instalados en contra de esa incorporación. Si la salud y la educación son de quienes pueden pagarlas, la capacidad de pago está preponderantemente destinada a quienes son de piel más clara, de estatura más alta, es decir, de "buena presentación”. Entre las dos civilidades han venido a intercalarse civilidades surgidas, como identidad y como afrenta, de entre los más morenos y de estatura más baja, esas civilidades son vestigios de los pícaros de finales del Siglo XVIII y principios del Siglo XIX, de los léperos de finales del Siglo XIX y principios del XX, y de los 'pelados' de finales del siglo XIX y de la primera mitad del siglo XX. Pero esas civilidades también son expresión de las prácticas de identificación social y psicológica de quienes fueron rechazados, antes de solicitar su ingreso a las capas superiores de la sociedad. La imposibilidad de acceder a las capas sociales superiores parece traducirse en el surgimiento de múltiples civilidades, la mayor parte de ellas ligadas a 'economías subterráneas 
alternativas'. Ese surgimiento no puede ser visto de otra manera sino como una desarticulación del entramado social.

\section{Bibliografía}

Arriagada, I. (2007). "Familias Latinoamericanas: Diversas, Cambiantes y Desiguales" Papeles de Población, 53: 9-22.

Bartra, R. (2002). Anatomía del Mexicano. México: Plaza y Janés.

Bazave Benítez, A. (1992). México Mestizo: Análisis del Nacionalismo Mexicano en torno a la Mestizofilia de Andrés Molina Enríquez. México: Fondo de Cultura Económica.

Blair, J. A. ( ). Groundwork in the Theory of Argumentation. New York: Springer.

Bonfil Batalla, G. (2005). México Profundo: Una Civilización Negada. México: Random House Mondadori.

Carrera, M. (2009). ““El Nuevo (Mundo) no se parece al Viejo”: Racial Categories and the Practice of Seeing”. Journal of Spanish Cultural Studies, 10, 1: 59-73.

Clarke, J. N. (2010). "The Portrayal of Depression in the three most popular English-Language Black-American Magazines in the USA: Ebony, Essence, and Jet" Ethnicity and Health, 15, 5: 459-573.

Casares Sánchez, J. (2000). Diccionario Ideológico de la Lengua Española. Barcelona Gustavo Gili.

Cope, R. D. (1994). The Limits of Racial Domination: Plebeian Society on Colonial Mexico City 1660-1720. Madison: The University of Wisconsin Press.

Cruz Flores A. y Galvez Vadillo E. (2007). El Tianguis de la Colonia San Felipe, en la Mira. La Jornada, lunes 23 de abril de 2007. www.lajornada.unam.mx)

Cuéllar, de, J. T. (1892). “El Aseo. La Urbanidad. La Policía y la Plebe.” En: J. T. de Cuéllar (Autor). La Linterna Mágica, Artículos Ligeros sobre Asuntos Trascendentales, por Facundo, Tomo XXII, Segunda Época. Santander, España: Imprenta y Litografía de L. Blanchard.

Chiappe, D. L. (2000). "Metaphor, Modularity, and the Evolution of Concept Integration.” Metaphor and Symbol, 15, 3: 137-158.

Díaz Guerrero, R. (1974). "La Mujer y las Premisas Histórico Socio-Culturales de la Familia Mexicana.” Revista Latinoamericana de Psicología, 6, 1: 7-16.

Dilthey, W. (1951). Psicología y Teoría del Conocimiento. México: Fondo de Cultura Económica.

Dosse, Francois (1998). The Empire of Meaning: The Humanization of Social Sciences. Minneapolis: The University of Minnesota Press.

Downie, D. A. (2010). "Baubles, Bangles, and Biotypes: A critical review of the use and abuse of the Biotype Concept.” Journal of Insect Science, 10, 176: 1-18.

Elias, N. (1990). La Sociedad de los Individuos. Barcelona: Península. 
Embree, L. (2004). “The Three Species of Relevancy in Gurwitsch.” Contributions to Phenomenology, Gurwitsch Relevancy for Cognitive Science. (Ed.) L. Embree, 52: 205-219.

Enciso Contreras, J. (1995). "Repúblicas de Españoles en la Nueva Galicia del siglo XVI.” Vínculo Jurídico, 22. http://www.uaz.edu.mx/vinculo/webrvj/Irv22.htm Consultado el 16 de agosto de 2011.

Fernández, E. (1943). María Candelaria. México: Película producida por Emilio Fernández.

Ferrando Badía, J. (1974). “Casta, estamento y Clase Social.” Revista de Estudios Políticos, 198: 23-66.

Ferraris, M. (2002). Historia de la Hermenéutica. México: Siglo XXI.

Giovannetti, J. L. (2004). "El Legado de Harry Hoetink: Relaciones Raciales y Estudios Caribeños.” Revista Mexicana del Caribe, 17: 209-238.

Gómez Robleda, J. (1961). Estudio Biotipológico de los Otomies. México: UNAM. Gómez de Silva, G. (1988). Breve Diccionario Etimológico de la Lengua Española. México: Colegio de México - Fondo de Cultura Económica.

Gurwitsch, A. (2002). Esquisse de la Phénomenologie Constitutive. Paris: Vrin.

Hering Torres, M. (2003-2004). ““Limpieza de Sangre” ¿Racismo en la Edad Moderna?” Tiempos Modernos, 9: 1-16.

Hoetink, H. (1967). The Two Variants in Caribbean Race relations: A Contribution to the Sociology of Segmented Societies. London: Institute of Race Relations.

INEGI (2011). Encuesta Nacional de Ingresos y Gastos de los Hogares.

http://www.inegi.org.mx/est/contenidos/Proyectos/Encuestas/Hogares/regulares/Eni gh/Enigh2010/tradicional/default.aspx

Jackson, R. H. (1999). Race, Caste, and Status: Indians in Colonial Spanish America. Alburquerque: The Universiy of New Mexico Press.

Jusidman, C. (2009). "Desigualdad y Política Social en México.” Nueva Sociedad, 220: 190-206.

Kamilamba, K. M. (2005). "Mestizaje y Racismo en la Representación Política en México.” Latinoamérica, Revista de Estudios Latinoamericanos, 40, 1: 245-263.

Katzew, I. (2004). La Pintura de Castas: Representaciones Raciales en el México del Siglo XVIII. México: CONACULTA.

Koselleck, R. (2012). Historias de Conceptos: Estudios sobre Semántica y Pragmática del Lenguaje Político y Social. Madrid: Trotta.

Koselleck, R. (1994). L'Expérience de l'Histoire. Paris: Hautes Études, Gallimard Le Seuil.

Lagunas Rodríguez, Z. y López Alonso, S. (2004). “Antropología Física en Grupos Humanos de Filiación Otopame.” Ciencia Ergo Sum, 11, 1: 47-58.

Levaggi, A. (2001). "República de Indios y República de Españoles en los Reinos de Indias.” Revista de Estudios Histórico-Jurídicos, 23: 419-428.

Lewis, L. A. (2006). Hall of Mirrors: Power, Witchcraft and Caste in Colonial Mexico. Durham, N.C.: Duke University Press.

Lomnitz Adler, L., y Pérez Lizaur, M. (2006). Una Familia de la Élite Mexicana: Parentesco, Clase y Cultura, 1820-1980. México: Miguel Ángel Porrua. 
Markus, K. A. (2008). "Constructs, Concepts and the Worlds of Possibility: Connecting the Mesurement, Manipulation, and Meaning of Variables." Measurement, 6: 54-77.

Martinez, M. E. (2008). Genealogical Fictions: Limpieza de Sangre, Religion and Gender in Colonial Mexico. Stanford: Stanford University Press.

Mayagoitia, A. (1998). "Linajes de Abogados en el México del Siglo XIX o cómo es que de casta le viene al galgo ser rabilargo." Anuario Mexicano de Historia del Derecho, 10: 537-595.

Merleau-Ponty, M. (1945). Phénoménologie de la Perception. Paris: Gallimard.

Monsivais, C. (2010). "No es que esté feo, es que estoy mal envuelto, je je (Notas sobre la estética de la naquiza).” NEXOS, 1 de octubre de 2010, sección: Especiales. NEXOS en línea.

Mörner, M. (1974). Estado, Razas y Cambio Social en Hispanoamérica Colonial. México: Sep-Setentas, Secretaría de Educación Pública.

Mörner, M. (1967). Race Mixture in the History of Latin America. NY: Little Brown and Co.

Myers, G. and Margavio, A. V. (1983). "The Black Bourgeoisie and Reference Group Change: A Content Analysis of Ebony.” Qualitative Sociology, 6, 4: 291308.

Navarro, C. (1936). Janitzio. México: Película producida por Crisóforo Peralta. Distribuida por Cinematográfica Mexicana.

Piedra Guillén, N. (2007). "Transformaciones en las Familias: Análisis Conceptual y Hechos de la Realidad.” Revista de Ciencias Sociales, 116: 35-56.

Pitt-Rivers, J. (1971). "On the Word of 'Casta'”. In: T. O. Beidelman (Ed.). The Translation of Culture: Essays to E. E. Evans Pritchard. London: Tavistock: 231-255.

Plunkett, D. (2011). "Expressivism, Representation, and the Nature of Concept Analysis.” Philosophical Studies, 156: 15-31.

Prieto, G. (2009). Memorias de mis tiempos. Xalapa: Universidad Veracruzana.

Psathas, G. (2004). "Alfred Schütz's influence on American Sociologists and Sociology.” Human Studies, 27, 1: 1-35.

Oriol Anguera, A. y Vargas Arreola F. (1983). El Mexicano: Raíces de la Mexicanidad. México: Instituto Politécnico Nacional.

Ramales Osorio, M. C. (2010). "México: Desigualdad Social y Pobreza. Saldos del “Gobierno del Empleo.”” Observatorio de la Economía Latinoamericana, 132, http://www.eumed.net/cursecon/ecolat/mx/2010/mcro2.htm

Ramírez Trejo, A. E. (2005). "Conciencia y Noción de Patria en Juan Zapata y Sandoval.” Pensamiento Novohispano, 6: 11-17.

Ramos, S. (1951). El Perfil del Hombre y la Cultura en México. Madrid: Colección Austral - Espasa Calpe.

Real Academia de la Lengua Española (1992). Diccionario de la Lengua Española. Madrid: Editorial Espasa Calpe.

Ritchie, L. D. (2004). "Lost in "Conceptual Space": Metaphores of Conceptual Integration.” Metaphor and Symbol, 19, 1: 31-50. 
Richter, M. (1994). "Begriffsgeschichte in Theory and in Practice: Reconstructing the History of Political Concepts and Language.” En: W. Melching and V. Velema (Eds.). Main Trends in Cultural History. Amsterdam, Netherlands: Editions Rodopi, B. V.: 121-149.

Robichaux, D. (2002). "El Sistema Familiar Mesoamericano y sus Consecuencias Demográficas.” Papeles de Población, 32: 60-95.

Rodríguez, I. (1957). Tizoc. México: Película producida por Ismael Rodríguez.

Rodríguez, I. (1952). Pepe el Toro. México: Película producida por Ismael Rodríguez.

Rodríguez, I. (1948). Nosotros los Pobres. México: Película producida por Ismael Rodríguez.

Rodríguez, I. (1948). Ustedes los Ricos. México: Película producida por Ismael Rodríguez.

Rozat Dupeyron, G. (2002). Indios Reales e Indios Imaginarios en los Relatos de la Conquista de México. Xalapa: Universidad Veracruzana.

Rozat Dupeyron, G. (2001). Los Orígenes de la Nación: Pasado Indígena e Historia Nacional. México D.F.: Universidad Iberoamericana.

Serra Rojas, A. (1994). Mexicanidad: Proyección de la Nación Mexicana hacia el Siglo XXI. México: Porrúa.

Simms, E. Y. (2008). "Miscegenation and Racism: Afro-Mexicans in Colonial New Spain.” Journal of Pan African Studies, 2, 3: 228-254.

Smith H. S. (1941). "Racial Segregation in Insect Populations and its Significance in Applied Entomology.” Journal of Economic Entomology, 34: 1-13.

Todorov, T. (1996). La Conquista de América: El problema del Otro. México: Siglo Veintiuno Editores.

Thimmesch, N. (1973). "John J. Johnson: The Man behind Ebony.” The Saturday Evening Post, 247, 7: 36-41.

Thorpe, W. H. (1930). "Biological Races in Insects and Allied Groups.” Biological Reviews, 5: 177-212.

Treviño Rangel, J. (2008). "Racismo y Nación: Comunidades Imaginadas en México.” Estudios Sociológicos, 26, 3: 669-694.

Turner, M. and Fouconnier, G. (1999). “A Mechanism of Creativity.” Poetics Today, 20, 3: 397-418.

Turner, M. and Fouconnier, G. (1995). "Conceptual Integration and Formal Expression.” Metaphor and Symbolic Activity, 10, 3: 183-204.

Urías Horcasitas, B. (2000-2001). "Medir y Civilizar.” Ciencias, 60-61: 28-36

Valenzuela Arce J. M. (2004). Decadencia y Auge de las Identidades: Cultura Nacional, Identidad Cultural y Modernización. México: Plaza y Valdez.

Vilas, C. M. (1996). "Mujeres Centralizadoras, Varones Dominantes, Familias Extensas: Una Aproximación a la Burguesía Mexicana.” Política y Cultura, 6: 173-180.

Villegas, A. (1960). La Filosofía de lo Mexicano. México: Fondo de Cultura Económica. 
White, M. (2006). “Ambivalent Civility”. Canadian Journal of Sociology, 31, 4: 445-460.

Wolf, E. R. (1967). Pueblos y Culturas de Centro América. México: ERA

Wright, R. and Ellis, M. (2006). "Mapping Others." Progress in Human Geography, 30: 285-288.

Yáñez, A. (1992). “Estudio Preliminar.” En: J. J. Fernández de Lizardi (Autor), El Pensador Mexicano. México: Universidad Nacional Autónoma de México: VLI.

Yehezkel, G. (2005). “A Model of Conceptual Analysis.” Metaphilosophy, 35, 5: 668-687.

Zirión Quijano A. (2009). La Fenomenología en México: Historia y Antología. México: Universidad Nacional Autónoma de México. 